\title{
Repairing of an Engine Block Through the Cold Gas Dynamic Spray Technology
}

\author{
Antonello Astarita $^{a}$, Fabrizio Coticelli ${ }^{a}$, Umberto Prisco $^{a *}$ \\ ${ }^{a}$ Dept. of Chemical, Materials and Industrial Production Engineering, University of Napoli Federico II, \\ Piazzale Tecchio 80, 80100, Napoli, Italy
}

Received: February 10, 2016; Revised: June 20, 2016; Accepted: August 11, 2016

\begin{abstract}
In the modern automotive industry, the maintenance of the vehicle during its life cycle is increasing in importance due to both economical and environmental considerations. A new frontier is the reparation of large parts, originally made by fusion, by the addition of material. The standard technique in the field is the use of TIG welding, but in the last few years Cold Dynamic Gas Spray (CDGS) has started to show many promises in supplanting TIG repairs. The main advantage of CDGS is the absence of thermal stresses in the repaired zone with the elimination of thermal distension treatment of the part. In this paper we study the use of CDGS to repair wear damage on a commercial aluminium engine block in comparison with the standard repair procedure with TIG. The result obtained shows that CDGS is an effective technology for industrial-level repair.
\end{abstract}

Keywords: Cold Spray, Aluminum, Engine Block Repairing, Welding.

\section{Introduction}

During the last decade Cold Gas Dynamic Spray (hereinafter called CGDS or simply Cold Spray) has been the object of great interest from both research community and industry, with several research papers, patents, and books published on this topic ${ }^{1,2}$. Nowadays cold spray is no more an experimental technology confined to the laboratory but has proven its ability to compete in the commercial field with older technologies, with special regards to the production of metallic coatings and the repair of damaged components ${ }^{3,4}$. CGDS is an additive manufacturing process in which a layer is deposited by means of high velocity impacts of metallic particles carried by a supersonic gas. Unlike other deposition technologies, in CGDS the bonding between the particles and the substrate is made at a comparatively low temperature, and as result the particles do not undergo phase changes ${ }^{5,6}$. Through the use of a converging/diverging nozzle (De Laval nozzle) a heated gas is pushed into a supersonic laminar flow. The metallic particles are dispersed into this flow and propelled to supersonic velocities, usually in the range between 500 and $1000 \mathrm{~m} / \mathrm{s}$. When the particle hit the substrate the high kinetic energy causes a phenomenon of macroscopic plastic deformation that embeds the particle on the substrate while preserving its crystalline structure ${ }^{7}$. For the bonding to succeed it is necessary that the kinetic energy of the single particle is higher than a threshold value ${ }^{8,9}$. The velocity at which the bonding is achieved is called critical velocity and it is function of the particle size and distribution as well as the substrate material. The coatings exhibit high density and conductivity, good corrosion resistance and high hardness, due to the cold worked microstructure ${ }^{10}$.

* e-mail: umberto.prisco@unina.it
Due to the absence of thermal stresses during the deposition process, CGDS results a repair technique suitable for a wide range of components, like turbine blades, pistons, cylinders, valves, rings, bearing components, pump elements. Some recent studies investigated this application for light alloy ${ }^{11,12}$, titanium ${ }^{13}$ and for cast iron ${ }^{14}$ components, which are not repairable with the usual technologies. The opportunity of using cold spraying for both additive manufacturing and part repair has not been missed by the industry. There are many patents, both approved and proposed, which take advantage of the comparative lack of heating for producing coatings with a determined phase structure that would not be obtainable with conventional hot methods.

Aluminum-based alloys engine blocks can undergo several types of damages. Sometimes, the compression in the cylinder can cause a leak though the gasket; a blown head gasket can occur in case of severe damage. The use of aluminum rather than iron cylinder heads has aggravated this problem, due to the greater thermal expansion of aluminum alloys and the subsequent greater stress transferred on the head gasket. In addition to the previous one, leaks due to problems occurring in the cooling system can take place. In this case, stray voltage through the coolant can produce an electrolytic action that can determine considerable block damage in a short period of time. The resulting damages can be erosion, pitting or cracks, up to the failure of the cylinder block. For these reasons, the wear and corrosion resistance are among the most important characteristics required from an engine block.

Usually, the damaged areas of the head or engine block are resurfaced if it is needed to restore the correct geometry in order to ensue the coupling with other parts, e.g. restoring the flatness of a damaged head engine so that the head gasket could seal properly. However, the engine block must be replaced in case of extensive damage. 
Considering that the replacement of these parts is very expensive, there is an increasing trend to develop repair processes capable of restoring the materials to an acceptable level of structural integrity and functionality. This topic is the focal points of the present paper.

Common techniques in use today to repair damages in large components are welding ${ }^{15}$ and bonding ${ }^{16}$. Welding entails some disadvantages; in particular, it causes high tensile residual stresses and produces alterations of the base material in the repaired zone. These effects deterirate the performance of the component, so that a post-weld heat treatment (PWHT) is usually required to relieve the residual stresses and restore the properties of the base material. In large components, PWHT can produce high distortions and usually requires long time. The use of CGDS, as an alternative to welding, prevents the formation of tensile residual stresses and alteration of the base metal; for these reasons, heat treatments after the repair are not required. This allows reduction of costs and avoids the risk of distortions that could compromise the reuse of the component. CGDS could also be used to repair/restore some areas of those components that cannot be repaired by welding. For example, it is not possible to repair thin walls with welding, due to the fact that the induced thermal stresses would severely modify the local microstructure compromising the properties of the base material.

The present work studies the feasibility of GDCS as a repair technique for aluminum engine blocks with particular focus on the microstructure, hardness and corrosion resistance of the restored zones. A comparison of the results obtained using welding and GDCS as repair technique was carried out. To this aim, artificial damages were produced on an aluminum engine block through machining. These damages were then repaired using both cold spray and TIG welding. The following investigations were carried out on both the repaired samples: metallographic observations, micro-hardness tests on the cross sections of the repair, and potentiodynamic polarization measurements to investigate the corrosion resistance.

\section{Experimental}

A commercial FIAT engine block was used for the experiments, Figure 1. Superficial damages were induced on the engine block through machining to reproduce possible damages that can occur during service. The engine block is made of A380 aluminum die casting alloy ${ }^{17}$; the chemical composition of this alloy is reported in Table 1. In particular, six different damages were produced: three were repaired through welding and three through cold spray. The samples to be repaired were cut from the engine block through hacksaw.

A sample repaired using TIG welding is shown in Figure 2 , with a section of the welded repair machined to obtain a flat surface. Before the welding, the sample was preheated

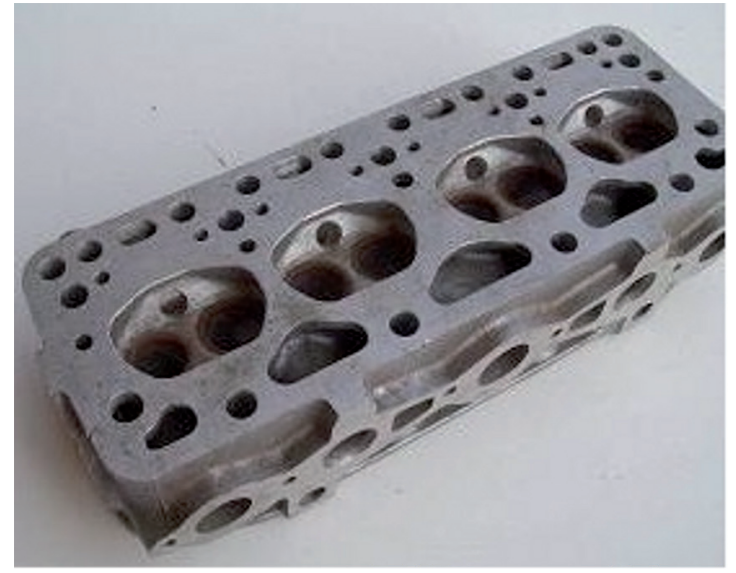

Figure 1: Engine block used in the experimentation.

at $100^{\circ} \mathrm{C}$. TIG welding was performed under the following parameters: direct current straight polarity, 100-130 A; voltage, $11 \mathrm{~V}$; welding speed, $100-140 \mathrm{~mm} / \mathrm{min}$ and argon flow rate, $8 \mathrm{LPM}$. The temperature was controlled after every pass with a thermocouple to limit the base metal alterations. The chosen filler metal was an AA4047 in form of wire, widely used in industry for repairing worn surfaces of hydraulic components, see Table 1. After welding, the sample was protected with mineral wool, to reduce the cooling rate and to avoid an excessive alteration of the base metal.

A sample repaired by using CGDS is shown in Figure 3. Before the CGDS a grit-blasting was carried out on the sample to improve the adhesion of the coating on the substrate material. A commercial white corundum grit of $0.6-0.7-\mathrm{mm}$ diameter was used. The blasting pressure was $0.6 \mathrm{MPa}$. An Al-12\% Si powder, with a composition very similar to the same Al-Si alloy used in the TIG process, was chosen for the cold spray repair, see Table 1 . The powder is characterized by a mean particle diameter of 40 microns. A SEM micrograph of the powder used is shown in Figure 4.

The powder was deposited using a low pressure Dymet 413 equipment, Figure 5, with nitrogen as carrier gas. The spray conditions were the following: the propellant gas was preheated to about $1000{ }^{\circ} \mathrm{C}$, the gas pressure was chosen equal to $2 \mathrm{MPa}$, the spray distance was fixed in $40 \mathrm{~mm}$, the particles velocity was fixed at $600 \mathrm{~m} / \mathrm{s}$ and the transverse speed of the gun was chosen equal to $0.01 \mathrm{~m} / \mathrm{s}$.

The specimens for the metallographic observations were cut from the cross section of the repaired samples to observe the microstructure of the repairing and of the base material. For the optical and SEM observations, the specimens were mounted in epoxy conductive resin and polished to mirror like finishing using standard procedures. In order to reveal the microstructure, the specimens have been etched by $0.5 \mathrm{wt} \% \mathrm{HF}$ solution. Moreover, to detect the presence of porosity, non-etched specimens have been observed by optical microscope. SEM observations were carried out with 
Table 1: Composition of the used alloys (all values are percentage by weight).

\begin{tabular}{lcccccccccc}
\hline & $\mathrm{Si}$ & $\mathrm{Fe}$ & $\mathrm{Cu}$ & $\mathrm{Mg}$ & $\mathrm{Mn}$ & $\mathrm{Ni}$ & $\mathrm{Zn}$ & $\mathrm{Sn}$ & Others & Aluminum \\
\hline A380 Al-Si alloy & 7.8 & 1.5 & 3.2 & 0.1 & 0.5 & 0.5 & 3 & 0.2 & 0.40 & balance \\
AA4047 Filler metal & 12 & 0.5 & 0.3 & 0.1 & 0.1 & & & & 0.03 & balance \\
Al-12\% Si powder & 12 & 0.3 & 0.1 & 0.1 & & & & & balance \\
\hline
\end{tabular}

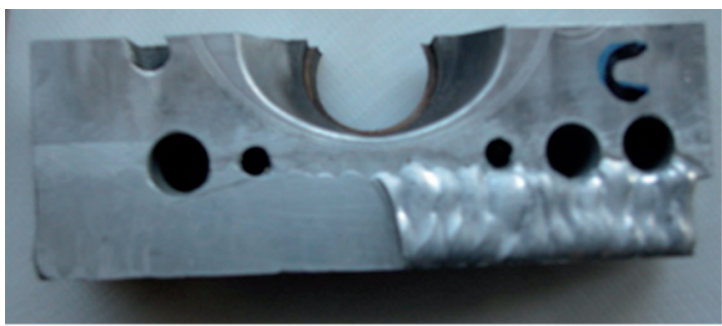

Figure 2: Macrograph of a sample repaired through TIG welding.

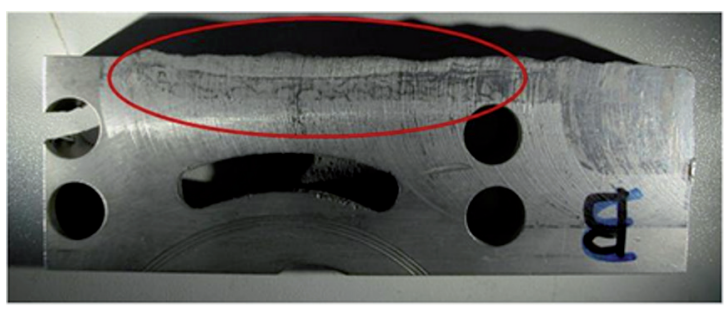

Figure 3: Macrograph of a sample repaired through CGDS; the red circle highlights the repaired zone.

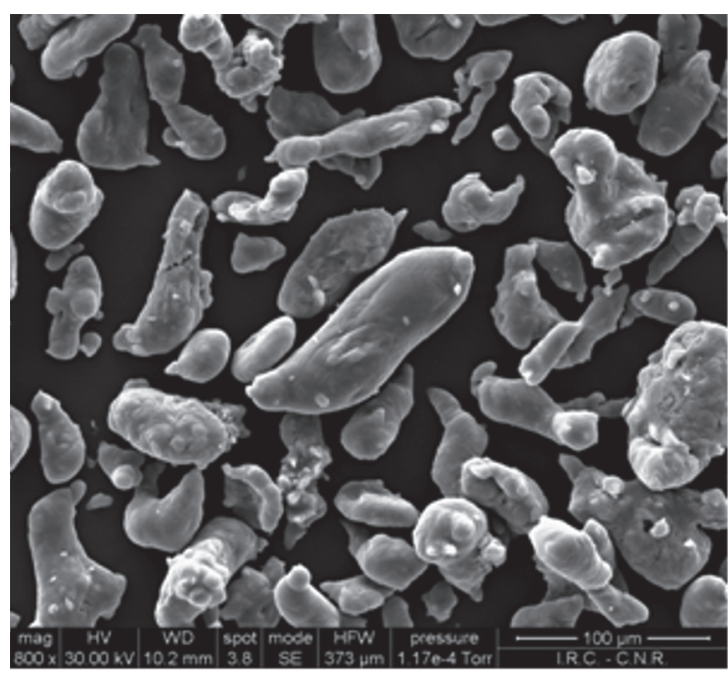

Figure 4: SEM micrograph of the powders used for the cold spray repairing.

a Hitachi TM 3000 scanning electron microscope, optical observations with a Leica MM6 metallographic microscope.

Micro hardness measurements were carried out, following the ASTM E 384 standard, by using a DAT equipment with a Vickers indenter and a load of $100 \mathrm{~g}$. Micro hardness has been measured not only on the repaired areas but also on the base material next to the welded section, to better understand the changes caused by the welded process on the material properties of the engine block.

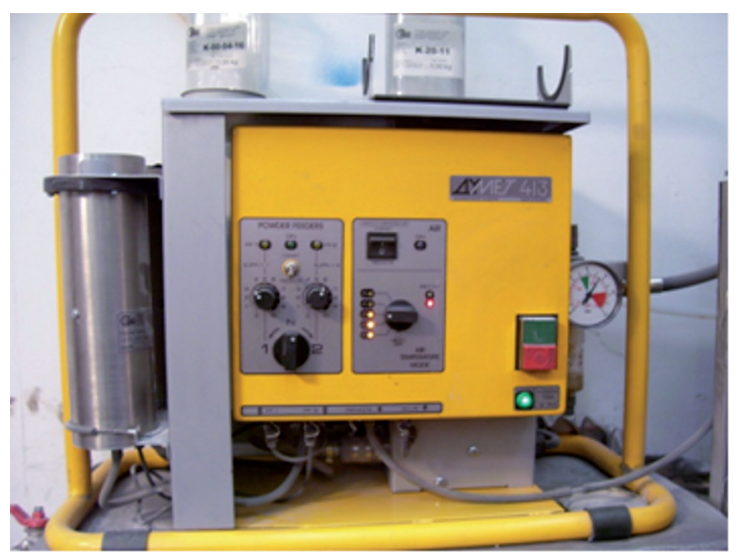

Figure 5: Low pressure Dymet equipment used for the spraying process.

The corrosion behavior of the repairs was investigated through potentiodynamic polarizations carried out on the top surface of the repairs. The area to be tested was degreased and polished in accordance to the ASTM standards. Measurements were carried out using a potentiostat (Biologic SP150) and a conventional electrochemical cell. A three-electrode configuration was used in this study, and an $\mathrm{Ag} / \mathrm{AgCl} 3 \mathrm{M} \mathrm{KCl}$ and $\mathrm{Pt}$ were used as the reference and the auxiliary electrode electrodes, respectively. Potentiodynamic polarizations have been carried out, after monitoring the Open Circuit Potential (OCP) for $1 \mathrm{~h}$, in the range from $-100 \mathrm{mV}$ vs OCP up to $1000 \mathrm{mV}$ vs Ag/ $\mathrm{AgCl}$ reference electrode at scan rate of 0.5 $\mathrm{mV} / \mathrm{s}$. Immersion tests in $\mathrm{NaCl} 3.5 \% \mathrm{wt}$ solution were carried out to further evaluate the corrosion behavior of the repairs.

\section{Results and Discussion}

Figure 6 shows the cross section of a cold spray repair. As expected the aluminum substrate is not affected by the cold spray process, even in the bonding zone the base material preserve the initial microstructure. This initial solidified morphology consists of large dendrite grains, which is a typical structure obtained by casting at higher superheating in absence of subsequent grain refinement processes.

From Figure 7, which shows a SEM micrograph of the repair cross section, it is possible to observe that the cold spray coating is quite compact and free from porosity.

Concerning the TIG repair detailed microstructural analysis are reported in Figure 8. In the repaired zone it is possible to observe a microstructure made of very small and thin lamellae, this is due to the very fast cooling experienced by the molten material in this zone. Are also visible the 


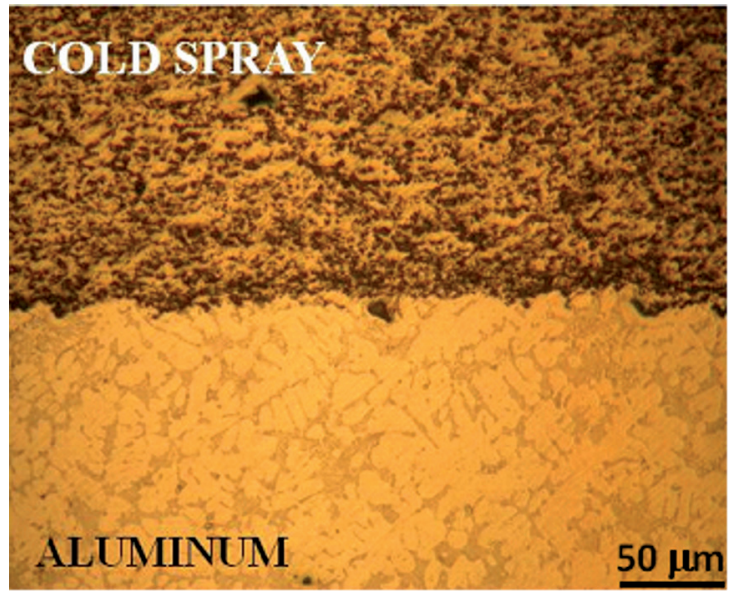

Figure 6: Cross section macrograph of the cold spray repair.

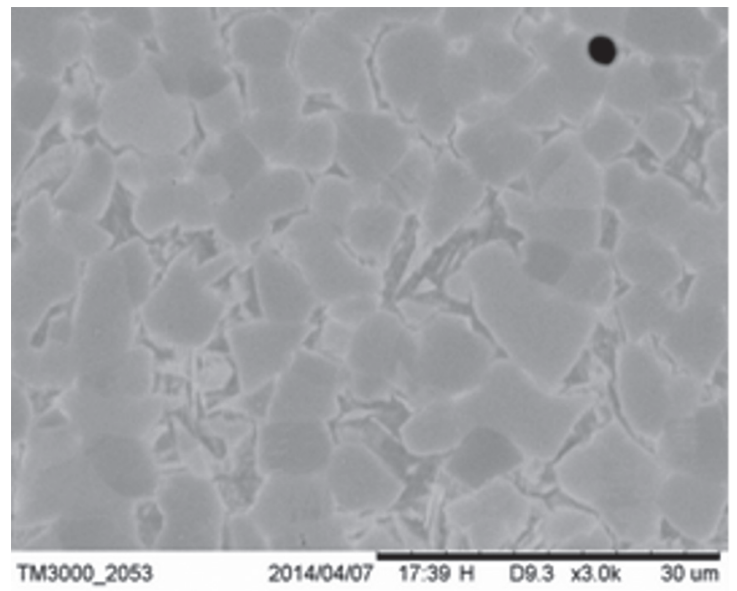

Figure 7: SEM micrographs of the cross section of the cold spray repair.

directions of the heat flow because the lamellae nucleate and grow up along this direction. The microstructure of the base material is coarser; in Figure 8(b) is clearly evident the interface between the base material and the welded repair. The substrate retains the initial microstructure also in this case; this suggests that the repairing method (described in the previous section) was effective in preserving the properties of the base material of the engine block. It is very difficult to identify the heat affected zone; in fact such a zone is not visible in the reported micrographs.

The polarization curves are reported in Figure 9. It is clear that the corrosion potential value of the base material is more positive than that of cold spray repair. Thus, the corrosion of the cold spray repair can take place in preference to the corrosion of base material. Furthermore, it is possible to assess from Figure 9 that the welding repair showed an electrochemical behavior similar to the one of the base material while the OCP potential of the cold spray repair is noticeably lower than the previous ones. This result suggests an anodic behavior of the cold spray repaired zone with respect to the material of the engine block ${ }^{8}$. The general trend of the curve is similar for all the three samples under investigation.

Photographs of the top surface of the specimens after the immersion test are reported in Figure 10 (welded repair) and 11 (cold spray repair). In particular, in both cases it is possible to observe the occurrence of classical pitting ${ }^{8,13}$. The cold spray repair shows a better behavior with respect to the welded repair, in particular very few pits are appreciable.

Lastly the results of the microhardness measurements are reported and discussed. An image of the indentation carried out in the cold sprayed repair is reported in Figure 12. The regular shape of the indentation is a clear indication that the deposited material is isotropic. Indeed, it is well known the relationships between the material anisotropy and the resultant indentation shape ${ }^{18}$. In particular, it was experimentally observed an increase of the distortion of the indentation with the anisotropy. The observed behavior is due to different plastic flows with regard to the crystals orientation and to differential elastic recovery on withdrawal of the indenter. Both effects can critically influence the sizes and shapes of hardness indentations. The results of the hardness measurements are given in Table 2 . The cold spray repair showed the same hardness of the base material, conversely the welded repair showed a higher hardness than the base material. This is due to the very fine grain structure of the welded zone, structure caused by the fast cooling of the same area.

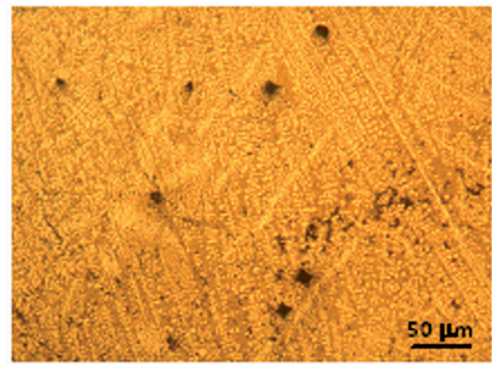

(a)

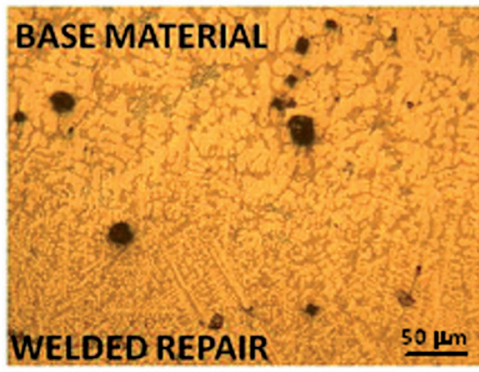

(b)

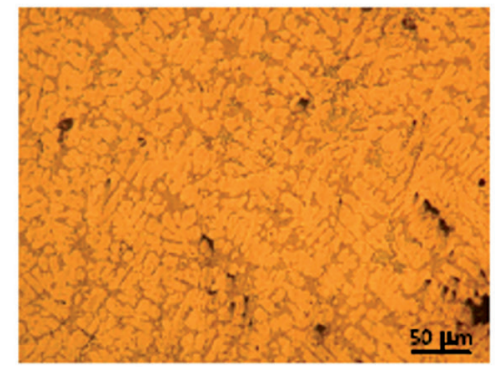

(c)

Figure 8: (a) Microstructure observed in the cross section of the welded repair; (b) microstructure of the welded repair near to the base material; (c) micrograph of the base material near to the repair. 


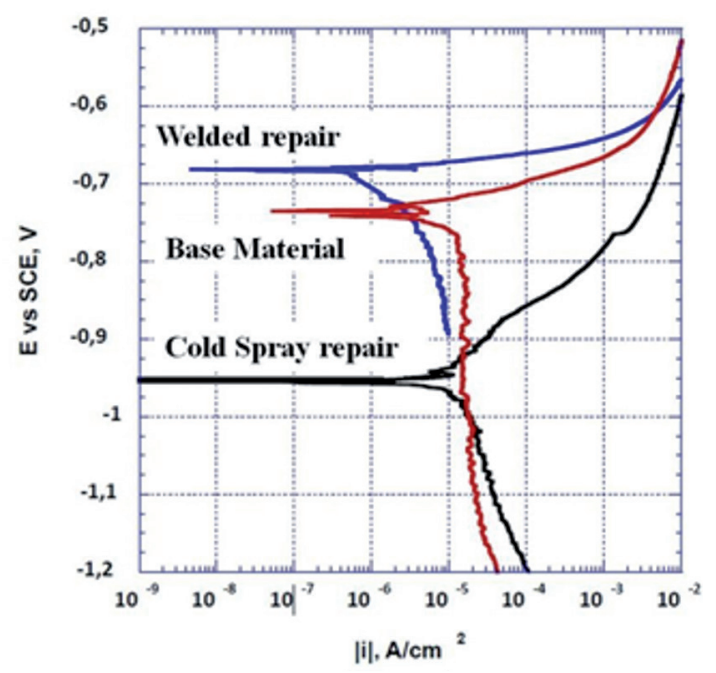

Figure 9: Results of the potentiodynamic polarization measurements.
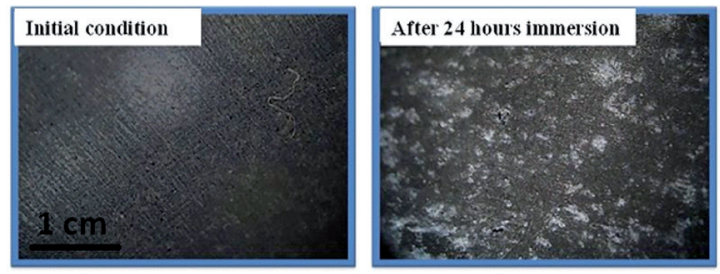

Figure 10: Macrograph of the top surface of the welded repair before and after the immersion test.
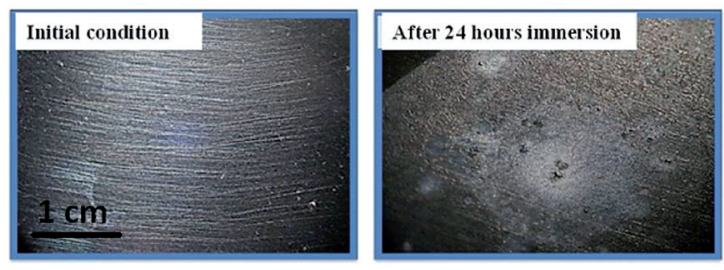

Figure 11: Macrograph of the top surface of the cold spray repair before and after the immersion test.

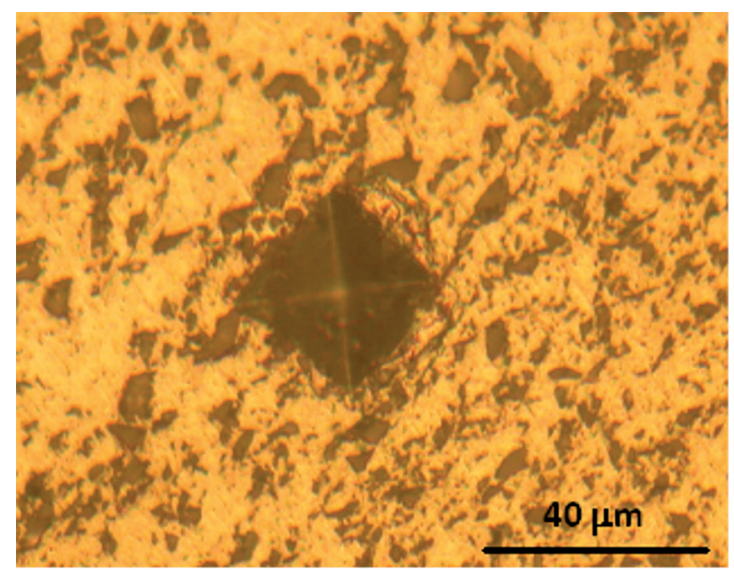

Figure 12: Vickers indentation on the cold sprayed repair.
Table 2: Results of the microhardness measurements.

\begin{tabular}{lccc}
\hline $\begin{array}{l}\text { Vickers micro } \\
\text { hardness }\end{array}$ & Base Material & $\begin{array}{c}\text { Welded } \\
\text { Repair }\end{array}$ & $\begin{array}{c}\text { Cold Sprayed } \\
\text { Repair }\end{array}$ \\
\hline Mean value & 72 & 86 & 70 \\
Dev. St. & 7.4 & 7 & 8 \\
\hline
\end{tabular}

\section{Conclusions}

The cold spray has been demonstrated to be an effective technique to repair damaged aluminum engine block. The repair obtained by cold spraying shows hardness values close to the one of the base material; moreover this repair is isotropic, as suggested by the regular shape of the indentations. The cold spray repair is also proven to be compact and free from defects. Concerning the corrosion behavior, the cold spray repair showed an OCP lower than the ones of the welded repair and of the base material. Regarding the immersion test the cold spray repair shows a better behavior with respect to the welded repair.

\section{References}

1. Cao F, Li H, Ning Z, Jia Y, Gu X, Yu L, et al. The formation mechanism of porosity for spray-deposited 7075 alloy. Materials Research. 2015;18(Suppl.1):89-94. http://dx.doi. org/10.1590/1516-1439.328414.

2. Maev RG, Leshchynsky V. Introduction to low pressure gas dynamic spray: physics \& technology. Weinheim: Wiley-VCH; 2008.

3. Elmquist B. Tagnite compatibility with aluminium cold spray repair of magnesium. In: Proceedings of National Association for Surface Finishing Annual Conference and Trade Show (SUR/ FIN 2013); 2013 Jun 10; Chicago: United States. p. 544-563.

4. Champagne V, Helfritch D. Critical assessment 11: structural repairs by cold spray. Materials Science and Technology. 2015;31(6):627-634. DOI: 10.1179/1743284714Y.0000000723.

5. Morgan R, Fox P, Pattison J, Sutcliffe C, O’Neill W. Analysis of cold gas dynamically sprayed aluminium deposits. Materials Letters. 2004;58(7-8):1317-1320. DOI: 10.1016/j. matlet.2003.09.048.

6. Marrocco T, McCartney DG, Shipway PH, Sturgeon AJ. Production of titanium deposits by cold-gas dynamic spray: numerical modeling and experimental characterization. Journal of Thermal Spray Technology. 2006;15(2):263-272. DOI: $10.1361 / 105996306 \times 108219$

7. Schmidt T, Gaertner F, Kreye H. New developments in cold spray based on higher gas and particle temperatures. Journal of Thermal Spray Technology. 2006;15(4):488-494. DOI: 10.1361/105996306X147144.

8. Astarita A, Durante M, Langella A, Montuori M, Squillace A. Mechanical characterization of low-pressure cold-sprayed metal coatings on aluminium. Surface and Interface Analysis. 2013;45(10):1530-1535. DOI: 10.1002/sia.5224. 
9. Prisco U. Size-dependent distributions of particle velocity and temperature at impact in the cold-gas dynamic-spray process. Journal of Materials Processing Technology. 2015;216:302314. DOI: $10.1016 /$ j.jmatprotec.2014.09.013

10. Irissou E, Legoux JG, Arsenault B, Moreau C. Investigation of $\mathrm{Al}-\mathrm{Al}_{2} \mathrm{O}_{3}$ cold spray coating formation and properties. Journal of Thermal Spray Technology. 2007;16(5-6):661-668.

11. Ajdelsztajn L, Schoenung JM, Jodoin B, Kim GE. Cold spray deposition of nanocrystalline aluminum alloys. Metallurgical and Materials Transactions A. 2005;36(3):657-666. http:// dx.doi.org/10.1007/s11661-005-0182-4.

12. van Steenkiste TH, Smith JR, Teets RE. Aluminum coatings via kinetic spray with relatively large powder particles. Surface and Coatings Technology. 2002;154(2-3):237-252. DOI: 10.1016/ S0257-8972(02)00018-X.

13. Lima RS, KucukA, Berndt CC, Karthikeyan J, Kay CM, Lindemann J. Deposition efficiency, mechanical properties and coating roughness in cold-sprayed titanium. Journal of Materials Science Letters. 2002;21(21):1687-1689. DOI: 10.1023/A:1020833011448.
14. Kim HJ, Lee CH, Hwang SY. Fabrication of WC-Co coatings by cold spray deposition. Surface and Coatings Technology. 2005;191(2-3):335-340. doi:10.1016/j.surfcoat.2004.04.058.

15. Fuentesa ARF, Alcântara NG, Rodríguez SH, Ibarra AL. Effect of in service weld repair on the performance of CrMo steel steam pipelines. Materials Research. 2006;9(2):153-158. http:/ dx.doi.org/10.1590/S1516-14392006000200008.

16. Benyahia F, Albedah A, Bouiadjra BAB. Elliptical and circular bonded composite repair under mechanical and thermal loading in aircraft structures. Materials Research. 2014;17(5):12191225. http://dx.doi.org/10.1590/1516-1439.259613.

17. ASM International. ASM Handbook, Volume 02 - Properties and Selection: Nonferrous Alloys and Special-Purpose Materials. Materials Park: ASM International; 1990.

18. Shimizu I, Tada N. Influence of crystallographic orientation upon microscopic indentation shape on pure titanium. Journal of the Society of Materials Science. 2008;57(3):249-254. http:// doi.org/10.2472/jsms.57.249 